\title{
Complete genome sequence and genetic organization of a Garlic virus D infecting garlic (Allium sativum) from northern India
}

\author{
J. SINGH' ${ }^{1}$, T. N. TRUONG ${ }^{2}$, D. M. AN ${ }^{2}$, M. R. PRAJAPATI ${ }^{1}$, A. MANAV ${ }^{1}$, N. B. QUOC ${ }^{2}$, K. RANJAN ${ }^{3}$,

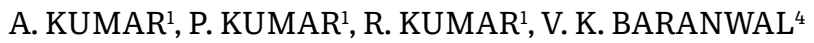

\begin{abstract}
${ }^{1}$ College of Biotechnology, Sardar Vallabhbhai Patel University of Agriculture and Technology, Meerut, Uttar Pradesh, India-250110; ${ }^{2}$ Research Institute for Biotechnology and Environment, Nong Lam University, Ho Chi Minh City, Vietnam; ${ }^{3}$ College of Veterinary and Animal Sciences, Sardar Vallabhbhai Patel University of Agriculture and Technology, Meerut, Uttar Pradesh, India-250110; ' Division of Plant Pathology, ICAR-Indian Agricultural Research Institute, New Delhi, India-110012
\end{abstract}

\begin{abstract}
Summary. - The present paper describes first full genome sequence of the Garlic virus D (GarV-D) from northern India with a genome size of $8425 \mathrm{bp}$ long ssRNA. The infected leaves and bulbs of garlic variety Yamuna Safed (G-282) plants suspected for GarV-D infection were collected with the aim to identify contagion virus during March, 2018. The total RNA was extracted from the pooled garlic plants using TRIzol reagent and sequenced using an Illumina HiSeq 2000 platform. BLASTn search in the NCBI database identified contagion as GarV-D (MK518067). It shared 83.63-85.83\% nucleotide sequence identities with other (GarV-D) isolates from Argentina (KF550407, KF555653, KR819505) and 83.15\% with isolates from China (MF795136, MF363012).
\end{abstract}

Keywords: Allium sativum; Allexivirus; Garlic virus D; India

\section{Introduction}

Garlic (Allium sativum), a spice or condiment, is used as carminative and gastric stimulant throughout India. The allicin present in aqueous extract of garlic reduces cholesterol concentration in human blood and inhalation of garlic oil or garlic juice is recommended in cases of pulmonary tuberculosis, rheumatism, sterility, impotency, cough and red eyes (Bayan et al., 2014). Garlic extracts also exhibit antibacterial, antifungal, antiviral and platelet activator properties in experimental conditions (Allison et al.,2012; Adler et al., 2002; Adetumbi et al., 1986; Nai-Lan et al., 1993).

India is a major garlic cultivating country and ranks second in total world production. It produces 1617.34

E-mail: jeets80@gmail.com; phone: +91-7017785669.

Abbreviations: $\mathrm{CP}$ = coat protein; GarV-D = Garlic virus D; NABP = nucleic acid binding protein; NTBP = viral nucleic acid binding protein, TGB = triple gene block protein metric tons of garlic from an area of 280.95 thousand hectares with the average production of 5.09 tons/ha (Patidar et al., 2018). Yamuna Safed (G-282) is one of the major varieties of garlic that has creamy white bulbs of about $4.5-6 \mathrm{~cm}$ in diameter with 15-16 cloves, mainly grown in Madhya Pradesh, Maharashtra, Haryana, Gujarat, Punjab, Rajasthan, Uttar Pradesh and Chhattisgarh states of India (Mishra and Vikram, 2017).

Production and productivity of garlic is limited by several biotic and abiotic factors, especially viral diseases that are responsible for decreasing yield and diminishing bulb and clove quality (Lunello et al.,2007). Due to sexual sterility, the agamic propagation of garlic is preferred, which results in natural infections by multiple plant viruses. The mixed viral infection in garlic results in mosaic pattern, chlorotic streaking, mottling, and twisting with curling of leaves and stunting of plants, that ultimately leads to the formation of small bulbs and cloves, and reduction in the yield up to the $78 \%$ (Conci et al., 2003; Lunello et al., 2007). To control such viral diseases, their molecular level identification is mandatory. The complete 


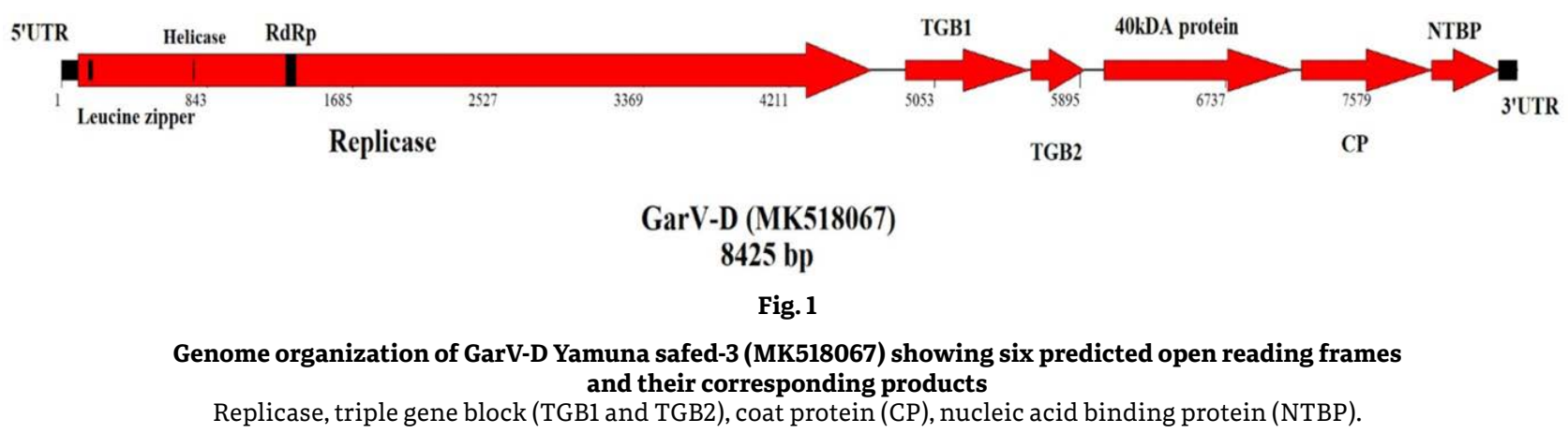

genome sequence-based study is one of the tools which can be employed for molecular characterization of Garlic virus D (GarV-D).

In India, six garlic viruses belonging to four different taxonomic groups namely, Allexivirus (Garlic virus X; Garv-X), Potyvirus (Onion yellow dwarf virus; OYDV and Leek yellow stripe virus; LYSV), Carlavirus (Garlic common latent virus; GarCLV and Shallot latent virus; SLV), Tospovirus (Iris yellow spot virus; IYSV) have been reported to infect garlic (Ghosh and Ahlawat, 1997; Majumder and Baranwal, 2009; Gawande et al., 2010; Baranwal et al., 2011; Gupta et al., 2013). Recently, GarV-D was identified and characterized in India with Allex-NABP (for amplification with generic allexivirus primers) or DCPF/DCPR primers (for amplification with GarV-D specific primers) (Khan et al., 2015, 2016; Chodorska et al., 2014).

\section{Materials and Methods}

Sample collection. The samples of infected leaves and bulbs of garlic cultivar Yamuna Safed (G-282) plants suspected for GarV-D infection were collected from Horticulture Research Centre, S. V. Patel University of Agriculture and Technology, Meerut during March, 2018. The collected samples were processed to detect and identify viruses infecting garlic plants.

Virus genome sequencing. To determine the causal agent(s), total RNA was isolated using TRIzol reagent (Chomoczynski, Sacchi, 1987) from a pooled sample of garlic plants. The small RNA deep-sequencing technology (Kreuze et al., 2009) was employed for virus identification. A small RNA library was prepared as described previously (Chen et al., 2012) and libraries were sequenced using an Illumina HiSeq 2000 at NxGenBio Life Sciences, New Delhi. Complete sequence of GarV-D genome identified in this study was deposited in GenBank Acc. No. MK518067 and designated as GarV-D Yamuna safed-3 isolate.

Confirmation of GarV-D by PCR. To reconfirm the GarV-D infection in the garlic plants, PCR primers (GarV-D-7000F 5'-GGGGCATGGTTTGTGTTAAGTT-3' and GarV-DR-8424
(5'-GTCGCGTGGACATAAGTTGTT-3') targeting CP and NTBP region were designed from the sequence with Acc. No. MF363012, to generate $\sim 1200 \mathrm{bp}$ product in RT-PCR. The viral RNA was isolated with Thermo Scientific GeneJET plant RNA purification mini kit (Thermo Scientific, USA) and RT-PCR reaction was performed with Thermo Scientific Revert Aid reverse transcriptase (Thermo Scientific) and DreamTaq DNA polymerase (Thermo Scientific). Thermocycling conditions consisted of 30 min at $52^{\circ} \mathrm{C}$, followed by denaturation for $30 \mathrm{~s}$ at $94^{\circ} \mathrm{C}$, primer annealing for $45 \mathrm{~s}$ at $58^{\circ} \mathrm{C}$ and elongation for $1 \mathrm{~min}$ at $72^{\circ} \mathrm{C}$ for 35 cycles, and a final elongation step of $10 \mathrm{~min}$ at $72^{\circ} \mathrm{C}$. The PCR amplicons were sequenced in the both directions by Sanger sequencing methods at DNA sequencing facility, Biokart India Pvt Ltd, Bangalore.

Bioinformatics data analysis. To identify possible viruses in garlic sample, ssRNA sequences were assembled and analyzed as previously described (Li et al.,2012). The sequence reads were assembled using CLC Genomic workbench 7.0.4 (CLC Bio) and genome annotated using Blast2GO. The pair wise nucleotide sequence identities were calculated using BioEdit version 7.05.3 software package (Hall et al., 1999) and phylogenetic analysis was done using MEGA X (Kumar et al., 2018).

\section{Results and Discussion}

Garlic plants in field conditions might be infected with Garlic virus D (GarV-D) and several other Garlic viruses such as Garlic virus A (GarV-A), Garlic virus B (GarV-B), Garlic virus C (GarV-C), Garlic virus E (GarV-E), Garlic virus X (GarV-X) etc. (King et al., 2012). In current study, upon high throughput sequencing sample yielded a total number of 34873264 reads and after trimming 199718 reads were mapped to the reference sequence submitted from China (Acc. No. MF363012).

In this study, for GarV-D, 7809 bp long near complete genome in form of single contig was obtained. The 5 and 3'UTR sequences were amplified by primers designed from the previously available GarV-D genome using 
primer blast software (https://www.ncbi.nlm.nih.gov/ tools/primer-blast/). Thus, verified complete genome of the GarV-D, reported in the present study comprised of 8425 nucleotides (Fig. 1) and was deposited in GenBank under the accession number MK518067 and designated as GarV-D isolate Yamuna safed-3 (G282). The genome sequence contained a 5'UTR (1-97 nt) and ORF 1 (98-4786 nt; $1562 \mathrm{aa}$ ) encoding a $176 \mathrm{kDa}$ polypeptide which is thought to be a virus-specific RNA replicase. A conserved motif SGx3Tx3NTx22GDD, which is the proposed active site of the RNA-dependent RNA polymerase (RdRp), was found at amino acid positions 1301-1359 aa (Fig. 2) and the NTP binding motif $\mathrm{Gx}_{2} \mathrm{Gx}_{1} \mathrm{GKS}$, which assumed to be involved in helicase activity, was found at position 765-772 aa. In addition to these, a leucine zipper pattern $\mathrm{L}-\mathrm{X}_{6}-\mathrm{LX}_{6}-\mathrm{L}-\mathrm{X}_{6}$ $\mathrm{L}$, which has not previously been described, was found at position 159-180 aa in present isolate. ORF 2 (4885-5598 $\mathrm{nt} ; 237 \mathrm{aa}$ ) encodes a $26 \mathrm{kDa}$ protein that has similarities to the TGB1 (triple gene block protein; pfam 01307). The TGB1, protein family have role in plant viral movement and include several known plant viral movement proteins from a number of different ssRNA plant virus families including potexviruses, hordeiviruses and carlaviruses. ORF3 (5612-5923 nt; $103 \mathrm{aa}$ ) encodes an $11 \mathrm{kDa}$ protein which has similarities to the TGB2 protein (pfam01443). TGB2 protein is homologous to those of other allexi-, carla- and potexviruses. ORF 4 (6034-7128 nt; $364 \mathrm{aa}$ ) encodes $40 \mathrm{kDa}$ serine rich protein (pfam05549). ORF 5 (7176-7928 nt; $250 \mathrm{aa)} \mathrm{en-}$ codes a $27 \mathrm{kDa}$ protein showing similarity to the viral coat protein (cl02836). ORF 6 (7928-8314 nt; $128 \mathrm{aa}$ ) encodes a 14 $\mathrm{kDa}$ protein which has similarities to the viral nucleic acid binding protein (NTBP) (cl05203) (Chen et al., 2001) and a 3'UTR that spans from 8315-8425 nt. BLASTn (Altschul et al., 1990) searches in the NCBI databases revealed that GarV-D Yamuna safed-3 shared $83.63-85.83 \%$ nucleotide sequence identities with other GarV-D isolates reported from Argentina (KF550407, KF555653, KR819505), 83.15\% with isolates from China (MF795136, MF363012).

During construction of $\mathrm{NJ}$ based phylogenetic tree with MEGA X (Kumar et al., 2018), GarV-D Yamuna safed-3 (MK518067) showed maximum identity to other isolates of GarV-D reported from Argentina (KF550407, KF555653, KR819505) (Celli et al., 2016) or China (MF795136, MF363012) and were grouped in the same clade (Fig. 3). Phylogenetic tree indicated that probably all reported isolates are closest to ancestral isolates.

The pairwise sequence identities of GarV-D Yamuna safed-3 with respective sequences of selected isolates of GarV-D from Argentina (KF550407, KF555653, KR819505) (Celli et al., 2016) and China (MF795136, MF363012) were generated at nucleotide level using BioEdit version 7.0.5.3 software package (Hall et al., 1999). At the nucleotide level, GarV-D Yamuna safed-3 sequence shared 82.9 to
IKK518067 GarV-D AHA90833 GarV-D ALK24278 GarV-D YP 008855206 GarV-D AVKK94126 GarV-D AGG13306 GarV-X NP 659010 GarV-B ABQ̄ 96641 GarV-B ABV51805 GarV-B AFV61767 GarV-X NP 569132 GarV-C AGG'13300 Garv-C ABV51816 GarV-C AGG13294 GarV-C

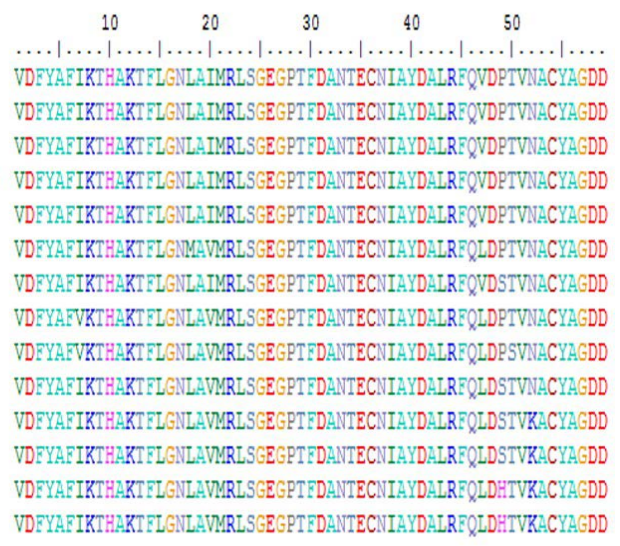

Fig. 2

Conserved motif sequences of active sites of RNA-dependent RNA polymerase (RdRp)

RNA-dependent RNA polymerase sequence with conserved motif $\mathrm{SGx}_{3} \mathrm{Tx}_{3} \mathrm{NTx}_{22}$ GDD of isolates GarV-D, GarV-X, GarV-E, GarV-B, and GarV-C.

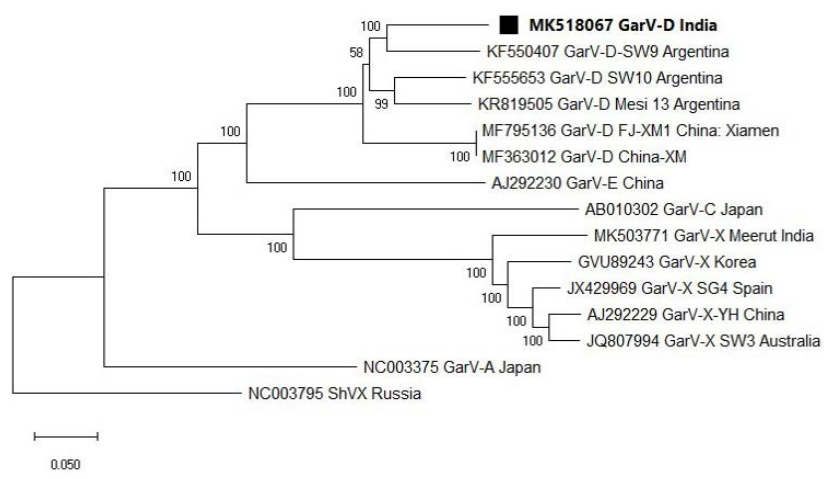

Fig. 3

Phylogenetic analysis of GarV-D isolates in the full length genome sequence using Neighbour joining algorithm of Mega $X$ software

The evolutionary distances were computed using p-distance method with 1000 bootstrap replicates. The scale bar indicates the number of substitutions per site. Shallot virus X (NC003795) was used as out-group.

85.5\% identities with these isolates (Table 1). The amino acid similarities of individual predicted open reading frames of GarV-D Yamuna safed-3 (MK518067) were also compared with other isolates of GarV-D (KF550407: Argentina; KF555653: Argentina; KR819505: Argentina; MF363012: China and MF795136: China) (Table 2). Bioinformatic analysis revealed that despite the wide geographic distribution and different growing conditions of hosts, GarV-D Yamuna safed-3 maintains an amino acid similarity between 94.8 to $96.8 \%$ and 89.8 to $91.4 \%$, with other isolates indicating high spatial and temporal genetic stability of the coat protein (CP) and nucleic acid binding 
Table 1. Pair wise comparison of nucleotide sequences of complete genome of GarV- D (Acc. No. MK518067) with other isolates of garlic viruses

MK518067 GarV-D India KF550407 GarV-D- Argentina KF555653 GarV-D Argentina KR819505 GarV-D Argentina MF795136 GarV-D China: Xm MF363012 GarV-D China-Xm MK503771 GarV-X India AJ292229 GarV-X-YH China JQ807994 GarV-X Australia GVU89243 GarV-X Korea JX429969 GarV-X SG4 Spain NC003375 GarV-A Japan AJ292230 GarV-E China AB010302 GarV-C Japan NC003795 ShVX Russia

\section{(a)}

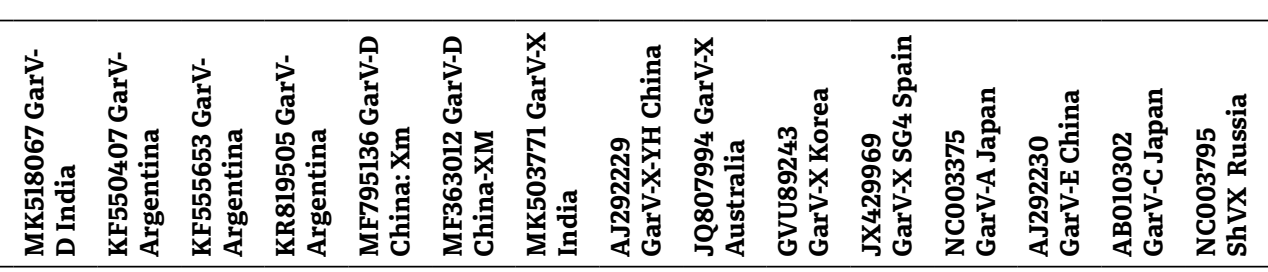

ID

$$
85.5 \text { ID }
$$

$83.7 \quad 84 \quad$ ID

$\begin{array}{llll}83.3 & 86.3 & 88.8 & \text { ID }\end{array}$

$\begin{array}{lllll}82.9 & 82.4 & 86.1 & 83 & \text { ID }\end{array}$

$\begin{array}{llllll}82.9 & 82.4 & 86.1 & 83 & 1 & \text { ID }\end{array}$

$\begin{array}{lllllll}59.2 & 59.9 & 58.9 & 59.3 & 59 & 59 & \text { ID }\end{array}$

$\begin{array}{llllllll}60.6 & 60.7 & 60.3 & 60.9 & 60.5 & 60.5 & 85.4\end{array}$

$\begin{array}{lllllllll}60 & 60.2 & 59.7 & 60.1 & 59.9 & 59.9 & 85.6 & 93.7 & \text { ID }\end{array}$

$\begin{array}{lllllllllll}59.6 & 59.5 & 58.8 & 59.6 & 59.4 & 59.4 & 83.8 & 87.9 & 86.5 & \text { ID }\end{array}$

$\begin{array}{lllllllllll}60 & 60.1 & 59.7 & 60.3 & 59.9 & 59.9 & 83.6 & 91.8 & 90.6 & 90.7 & \text { ID }\end{array}$

$\begin{array}{llllllllllll}61.7 & 61.3 & 61.8 & 61.8 & 61.6 & 61.6 & 55.3 & 56 & 55.6 & 55.3 & 55.7 & \text { ID }\end{array}$

$\begin{array}{lllllllllllll}69.2 & 69.4 & 70 & 69.6 & 69.8 & 69.8 & 59.4 & 60 & 59.7 & 59.1 & 59.5 & 60.9 & \text { ID }\end{array}$

$\begin{array}{llllllllllllll}60.6 & 60.5 & 60.2 & 60.7 & 60.7 & 60.7 & 63.7 & 64.8 & 63.7 & 63.7 & 64 & 55.8 & 60.5 & \text { ID }\end{array}$

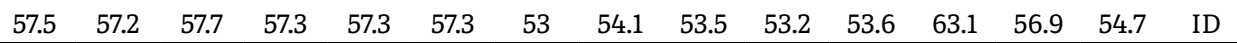

Table 2. Percentage amino acid sequence identity of pair wise combination of replicase, TGB 1, TGB 2, ORF 4 (serine rich protein), coat protein, ORF6 (nucleic acid binding protein) of GarV-D (Acc. No. MK518067) with other complete sequences of GarV-D isolates

\begin{tabular}{|c|c|c|c|c|c|c|c|c|c|c|c|c|}
\hline \multirow[t]{2}{*}{ Garlic virus D (GarV-D) isolates } & 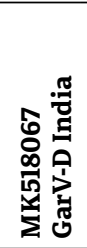 & 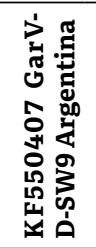 & 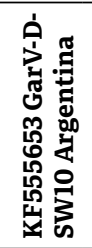 & 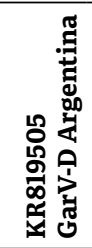 & & 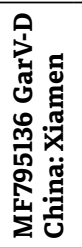 & 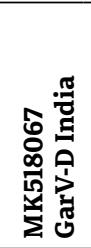 & 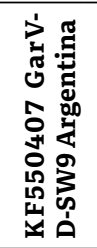 & 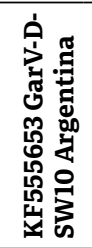 & 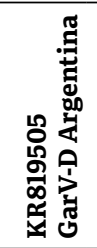 & 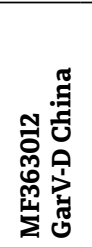 & 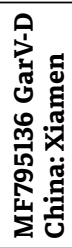 \\
\hline & \multicolumn{6}{|c|}{ replicase } & \multicolumn{6}{|c|}{ triple gene block protein 1} \\
\hline MK518067 GarV-D India & ID & & & & & & ID & & & & & \\
\hline KF550407 GarV-D-SW9 Argentina & 92.9 & ID & & & & & 86.4 & ID & & & & \\
\hline KF555653 GarV-D-SW10 Argentina & 91.5 & 91.5 & ID & & & & 83.9 & 86.9 & ID & & & \\
\hline KR819505 GarV-D Argentina & 91.4 & 90.9 & 95.7 & ID & & & 86.9 & 91.5 & 86.9 & ID & & \\
\hline MF363012 GarV-D China & 91.4 & 91.8 & 91.4 & 91.6 & ID & & 84.8 & 86 & 89 & 86.9 & ID & \\
\hline \multirow[t]{2}{*}{ MF795136 GarV-D China:Xiamen } & 91.4 & 91.8 & 91.4 & 91.6 & 100 & ID & 84.8 & 86 & 89 & 86.9 & 100 & ID \\
\hline & \multicolumn{6}{|c|}{ triple gene block protein 2} & \multicolumn{6}{|c|}{ ORF 4 (serine rich protein) } \\
\hline MK518067 GarV-D India & ID & & & & & & ID & & & & & \\
\hline KF550407 GarV-D-SW9 Argentina & 89.3 & ID & & & & & 78.0 & ID & & & & \\
\hline KF555653 GarV-D-SW10 Argentina & 90.2 & 88.3 & ID & & & & 80.7 & 75.5 & ID & & & \\
\hline KR819505 GarV-D Argentina & 89.3 & 96.1 & 91.2 & ID & & & 76.6 & 95.0 & 75.2 & ID & & \\
\hline MF363012 GarV-D China & 88.3 & 90.2 & 88.3 & 90.2 & ID & & 79.3 & 73.6 & 88.4 & 73.3 & ID & \\
\hline \multirow[t]{2}{*}{ MF795136 GarV-D China: Xiamen } & 88.3 & 90.2 & 88.3 & 90.2 & 100 & ID & 79.3 & 73.6 & 88.4 & 73.3 & 100 & ID \\
\hline & \multicolumn{6}{|c|}{ coat protein } & \multicolumn{6}{|c|}{ ORF6 (nucleic acid binding protein) } \\
\hline MK518067 GarV-D India & ID & & & & & & ID & & & & & \\
\hline KF550407 GarV-D-SW9 Argentina & 96.8 & ID & & & & & 91.4 & ID & & & & \\
\hline KF555653 GarV-D-SW10 Argentina & 95.2 & 95.6 & ID & & & & 89.8 & 92.9 & ID & & & \\
\hline KR819505 GarV-D Argentina & 96.8 & 96.4 & 96.0 & ID & & & 85.9 & 91.4 & 87.5 & ID & & \\
\hline MF363012 GarV-D China & 96.8 & 96.4 & 96.0 & 100 & ID & & 89.8 & 94.5 & 93.7 & 89.0 & ID & \\
\hline MF795136 GarV-D China: Xiamen & 94.8 & 95.2 & 96.8 & 94.8 & 94.8 & ID & 89.8 & 94.5 & 93.7 & 89.0 & 100 & ID \\
\hline
\end{tabular}


protein (NABP) genes (Table 2). Similarly, GarV-D Yamuna safed-3 (MK518067) also showed amino acid identities of 91.4-92.9\% in replicase, $83.9-86.4 \%$ in TGB1, 88.3-90.2\% in TGB2 and 76.6-80.7\% in serine rich protein regions with other GarV-D viruses (Table 2).

The 5' and 3'UTR sequence of GarV-D Yamuna safed-3 shared $97.3 \%$ nucleotide sequence identity with other GarV-D isolates from Argentina (KR819505, KF550407); China (MF795136, MF363012) and UK (L38892); 96.4\% with Korea (AF519572), Argentina (KF555653) and Japan (AB010303) isolates and 89.3\% with Spain (KF632716), Australia (JX997951), and Japan (AB010300) isolates. In 5'and 3'UTR regions highly conserved regions were perceived. Phylogenetic analysis of 5 ' and 3 'UTR sequences indicates very low diversity.

From the preliminary sequence assemblies and analyses, in addition to a near complete sequence of GarV-D, several other viruses, including Garlic virus X (GarV-X), Garlic common latent virus (GarCLV) and Leek yellow stripe virus (LYSV) were also identified. Owing to mixed infection, the disease symptoms observed could not be attributed to a single virus alone.

The garlic plants, which were tested positive for GarV-D, were again tested for GarV-D using primers set GarV-D7000F/ GarV-D-8424 R and revealed an amplification of $\sim 1200 \mathrm{bp}$. The nucleotide sequences of CP and NTBP region (1223 bp) were submitted to GenBank under the Acc. No. MN996259. In Blast analysis, the sequence showed maximum nucleotide identity of $81.10 \%$ with $93.5 \%$ query coverage to GarV-D isolate-591 from Spain (KX889819), GarV-D isolate 619 from China (KX889806) and 87.2\% identity with GarV-D from Korea (AF519572) with 97\% query coverage. GarV-D, Meerut (MN996259) showed an identity of $76.2-76.6 \%$ at nucleotide level and $89.9 \%$ at amino acid level with partial sequence of CP and NTBP region submitted from Ludhiana, Punjab, India under Acc. No. KP862055 and KR534889, respectively.

The virus isolates identified from different regions of the globe showed that all known isolates have diverged from a common ancestor isolates. In due course of time, they might have spread to different geographical regions by different means such as transport of biological material of plant origin, etc. (Bereda et al., 2015, 2017). GarV-D in garlic plants was earlier reported in Pacific Northwest (Gieck et al., 2009), Democratic Republic of Congo (Majumder et al., 2018), Poland (Chodorska et al., 2013; Bereda et al., 2015) and Australia (Wylie et al., 2014).

Based on phylogenetics, genomics analysis and available information in scientific databases, to the best of our knowledge, this is first report of the complete genome sequence of Garlic virus D from Allium sativum variety Yamuna Safed (G-282) from India. This report will encourage researchers to investigate impact of this virus on garlic production in India and reinforce the need of a garlic-seed certification programme to improve the health conditions of the crop. However, biological studies are needed to identify mechanisms of transmissions and to assess effects of single/mixed infection on garlic plants.

Acknowledgments. The authors acknowledge the Vice Chancellor, Sardar Vallabhbhai Patel University of Agriculture and Technology, Meerut-250110, Uttar Pradesh, Bioinformatics facility, Department of Biotechnology, India and ASEAN-India Science, Technology \& Innovation Cooperation, Department of Science \& Technology, India for providing financial support and the facilities to carry out this research work.

\section{References}

Adetumbi M, Javor GT, Lau BH (1986): Allium sativum (garlic) inhibits lipid synthesis by Candida albicans. Antimicrob. Agents Chemother. 30, 499-501. https://doi. org/10.1128/AAC.30.3.499

Adler BB, Beuchat LR (2002): Death of Salmonella, Escherichia coli 0157:H7, and Listeria monocytogenes in garlic butter as affected by storage temperature. J. Food Prot. 65, 1976-1980. https://doi.org/10.4315/0362028X-65.12.1976

Allison GL, Lowe GM, Rahman K (2012): Aged garlic extract inhibits platelet activation by increasing intracellular cAMP and reducing the interaction of GPIIb/IIIa receptor with fibrinogen. Life Sci. 91, 1275-1280. https://doi. org/10.1016/j.lfs.2012.09.019

Altschul S, Gish W, Miller W, Myers EW, Lipman DJ (1990): Basic Local Alignment Search Tool. J. Mol. Biol. 215, 403-441. https://doi.org/10.1016/S0022-2836(05)80360-2

Baranwal VK, Singh P, Jain RK, Joshi S (2011): First report of garlic virus $\mathrm{X}$ infecting garlic in India. Plant Dis. 95, 1197. https://doi.org/10.1094/PDIS-03-11-0198

Bayan L, Koulivand PH, Gorji A (2014): Garlic: a review of potential therapeutic effects. Avicenna J. Phytomed. 4(1), 1-14.

Bereda M, Kalinowska E, Paduch-Cichal E, Szyndel MS (2015): Low genetic diversity of a natural population of Garlic virus D from Poland. Eur. J. Plant Pathol. 142, 411-417. https://doi.org/10.1007/s10658-015-0615-x

Bereda M, Paduch-Cichal E, Dabrowska E (2017): Occurrence and phylogenetic analysis of allexiviruses identified on garlic from China, Spain and Poland commercially available on the polish retail market. European J. Plant Pathol. 149, 227-237. https://doi.org/10.1007/s10658$\underline{\text { 017-1171-3 }}$

Celli MG, Perotto MC, Buraschi D and Conci VC (2016): Biological and molecular characterization of Garlic virus D and its effects on yields of garlic. Acta Hortic. 1143,193-200. https://doi.org/10.17660/ActaHortic.2016.1143.28

Chen YR, Zheng Y, Liu B, Zhong S, Giovannoni J, Fei Z (2012): A cost-effective method for Illumina small RNA- 
Seq library preparation using T4 RNA ligase 1 adenylated adapters. Plant Methods 8, 41. https://doi. org/10.1186/1746-4811-8-41

Chen J, Adams MJ (2001): Molecular characterisation of a complex mixture of viruses in garlic with mosaic symptoms in China. Archives Virol. 146, 1841-1853. https://doi.org/10.1007/s007050170037

Chodorska M, Paduch-Cichal E, Kalinowska E, Szyndel MS (2013): Occurrence of the viruses belonging to the Allexivirus genus on garlic plants in Poland. Prog. Plant Prot. 53, 605-609. https://doi.org/10.14199/ppp2013-070

Chodorska M, Paduch-Cichal E, Kalinowska E, Szyndel MS (2014): Assessment of allexiviruses infection in garlic plants in Poland. Acta Sci. Pol. 13, 179-186.

Chomoczynski P, Sacchi N (1987): Single step method of RNA isolation by acid guanidinium thiocyanate-phenolchloroform extraction. Anal. Biochem. 162, 156-159. https://doi.org/10.1016/0003-2697(87)90021-2

Conci VC, Canavelli A, Lunello P (2003): Yield losses associated with virus-infected garlic plants during five successive years. Plant Dis. 87, 1411-1415. https://doi.org/10.1094/ PDIS.2003.87.12.1411

Gawande SJ, Khar A, Lawande KE (2010): First report of Iris yellow spot virus on garlic in India. Plant Dis. 94, 1066. doi:11094/PDIS-94-8-1066C. https://doi.org/10.1094/ PDIS-94-8-1066C

Ghosh DK, Ahlawat YS (1997): Filamentous viruses associated with mosaic disease of garlic in India. Indian Phytopathol. 50, 266-267.

Gieck, S L, Hamm PB, David NL, Pappu HR (2009): First report of Garlic virus B and Garlic virus D in garlic in the Pacific northwest. Plant Dis. 93, 431. https://doi.org/10.1094/ PDIS-93-4-0431A

Gupta N, Prabha K, Islam S, Baranwal VK (2013): First report of Leek yellow stripe virus in India from garlic. J. Plant Pathol. 95, 69-77.

Hall TA (1999): BioEdit: a user-friendly biological sequence alignment editor and analysis program for Windows 95/98/NT. Nucl. Acids. Symp. Ser. 41, 95-98.

Khan I, Sharma A, Dhatt AS, Kang SS, Kaur G (2015): First report of Garlic virus D infecting onion in India. J. Plant Pathol. 97, S69.

Khan I, Sharma A, Kang SS, Kaur G, Dhatt A (2016): Molecular characterization and identification of Garlic virus D associated with garlic in India. J. Plant Pathol. 98,607609. King AMQ, Adams MJ, Carstens EB, Lefkowitz EJ
(2012): Virus Taxonomy: Classification and Nomenclature of Viruses: Ninth Report of the International Committee on Taxonomy of Viruses. London, Waltham: Academic Press.

Kreuze JF, Perez A, Untiveros M, Quispe D, Fuentes S, Barker I, Simon R (2009): Complete viral genome sequence and discovery of novel viruses by deep sequencing of small RNAs: A generic method for diagnosis, discovery and sequencing of viruses. Virology 388, 1-7. https://doi. org/10.1016/i.virol.2009.03.024

Kumar S, Stecher G, Li M, Knyaz C, Tamura K (2018): MEGA $\mathrm{X}$ : Molecular Evolutionary Genetics Analysis across Computing Platforms. Mol. Biol. Evol. 35, 1547-1549. https://doi.org/10.1093/molbev/msy096

Li R, Gao S, Hernandez AG, Wechter WP, Fei Z, Ling K-S (2012): Deep sequencing of small RNAs in tomato for virus and viroid identification and strain differentiation. PLoS One 7, e37127. https://doi.org/10.1371/journal. pone.0037127

Lunello P, Di Rienzo J, Conci VC (2007): Yield loss in garlic caused by leek yellow stripe virus Argentinean isolate. Plant Dis. 91,153-158. https://doi.org/10.1094/PDIS-91-2-0153

Majumder S, Baranwal VK (2009): First report of Garlic common latent virus in garlic from India. Plant Dis. 93, 106. https://doi.org/10.1094/PDIS-93-1-0106C

Majumder S, Mbay K, Singh J (2018): First report of garlic virus D in garlic from D.R. Congo. J. Plant Pathol. 100, 143. https://doi.org/10.1007/s42161-018-0033-y

Mishra TD, Vikram B (2017): Evaluation of Garlic (Allium sativum L.) germplasms for yield potential and quality characters under Allahabad agro-climatic conditions. J. Pharmacogn. Phytochem. 6, 433-436.

Nai-Lan G, Cao-Pei L, Woods GL, Reed E, Gui-Zhen Z, Li-Bi Z, Waldman RH (1993): Demonstration of antiviral activity of garlic extract against human cytomegalovirus in vitro. Chin. Med. J. 106, 93-96.

Patidar PK, Khan N, Kumar S (2018): An economic analysis of Garlic cultivation in Ratlam district of Madhya Pradesh. Int. J. Agric. Environ. Biotechnol. 11, 371-377.

Wylie SJ, Li H, Saqib M, Jones MG (2014): The global trade in fresh produce and the vagility of plant viruses: a case study in garlic. PLoS One 9, e105044. https://doi.org/10.1371/ journal.pone.0105044 